\title{
Analyzing Alternative Intraday Credit Policies in Real-Time Gross Settlement Systems
}

\author{
Craig Furfine ${ }^{*}$ \\ Economist, Division of Reserve Bank Operations and Payment Systems \\ Mail Stop 188 \\ Board of Governors of the Federal Reserve System \\ Washington, DC 20551 \\ furfinec@frb.gov \\ Jeff Stehm \\ Manager, Division of Reserve Bank Operations and Payment Systems \\ Mail Stop 188 \\ Board of Governors of the Federal Reserve System \\ Washington, DC 20551 \\ stehmj@frb.gov
}

August 11, 1997

\begin{abstract}
This paper examines a central bank's choice of intraday credit policy for Real-Time Gross Settlement (RTGS) systems. Formal analysis of central bank objectives and commercial bank payment activity provides insight into both the choice and effects of several possible intraday credit policies. Observed intraday credit policies are interpreted within the context of the model. Among G-10 central banks, different combinations of prices, collateral, and quantity limits have been chosen to manage the supply of intraday credit. Conditions that rationalize these choices are shown to rely on a) central bank preferences regarding credit risk and systemic risk, b) liquidity management technologies. and c) the cost of collateral.
\end{abstract}

\footnotetext{
* The authors wish to thank colleagues in the Payment System Studies and Payment System Risk sections at the Federal Reserve Board of Governors, and participants at the Federal Reserve Bank of Chicago's Bank Structure Conference. The views expressed are those of the authors and do not necessarily represent the views of the Federal Reserve Board or the Federal Reserve System.
} 


\section{Introduction}

Modern economies generate payment activity that is many multiples of the value of a nation's real product. In the G-10 countries in 1994, large value payment flows were as large as 100 times annual GDP. In the United States, in 1994, large-value payment flows exceeded 70 times GDP (Bank for International Settlements 1995). To date, much of this payment activity has been handled by systems that settle on a net, rather than on a gross basis. As is well documented elsewhere, net settlement systems have the possibility to create systemic risk in the payments system (Van den Bergh 1994, Horii and Summers 1994, Borio and Van den Bergh 1993, Summers 1991, and Juncker, Summers, and Young 1991). As these authors discuss, without proper risk controls, failure of a net debtor in a net settlement system to meet its settlement obligation may cause other participants to face unexpected and significant liquidity shortfalls, credit losses, or both as a result of the settlement failure.

Because of systemic risks in the payment system and the desire to provide timely access to reserves for use in settlement, central banks have been increasingly interested in systems that process large-value payments using Real-Time Gross Settlement (RTGS) (European Union 1992, 1993). RTGS systems process and settle payment instructions individually, immediately, and with finality throughout the day across accounts held at the central bank. Given the intraday finality of RTGS payments, if a participant fails during the day, other participants who have received such payments during the day from the failing member will be unaffected. Hence, systemic risk in the RTGS system is eliminated through the central bank guarantee of finality. As a result of the systemic risk benefits of RTGS, such systems have begun to emerge in many countries as a competing or, in some cases, the replacement form of system designed to processes large value payments.' The European Union countries, for example, are all installing RTGS systems. These systems, in turn, will be linked through the proposed Trans-European Automated Real-Time Gross Express Transfer (TARGET) system as a necessary pre-condition for monetary union (European Union 1992,1993, Giannini and Monticelli 1995). Numerous Asian and Pacific Rim countries have also implemented or are 
moving toward implementation of RTGS systems, including Australia, Hong Kong, Thailand, and China (BIS 1997).

Central bank encouragement notwithstanding, commercial banks may be reluctant to process payments using a RTGS system because of certain costs that the system imposes on its participants. To settle each transaction on a real-time gross basis, a bank must either have the necessary funds in its central bank account at the time the payment is processed or be granted intraday credit by the central bank. ${ }^{2}$ These two possible sources of funds, central bank account balances (reserves) and central bank intraday credit, are thus the sources of liquidity for making payments. Holding non-interest bearing reserves overnight for settling payments during the day entails a significant opportunity cost to commercial banks and cost effective, intraday money markets do not yet exist for obtaining intraday funds.

As an alternative to holding additional overnight balances, a bank can manage its existing balances more efficiently. For example, instead of sending payments through the RTGS system immediately, a bank can wait for incoming payments to increase its intraday funds. Such queuing, however, may also increase costs by increasing the risk that time-critical payments will not be made by the end of the day. In the extreme, delays may lead to payment system gridlock where all participants are waiting for incoming payments without any outgoing payments being made. ${ }^{3}$

Because holding additional overnight balances and queuing payments may be quite costly, the cost of intraday central bank credit is an important factor in determining the cost of RTGS for commercial banks, and therefore, the willingness of banks to participate in RTGS systems. The model presented in this paper demonstrates how central bank policies regarding the provision of intraday credit determine a significant portion of a bank's cost of using an RTGS system. It does so by explicitly modeling the costs of managing liquidity, along with the costs of the intraday credit policies of the central bank. The model further explains why

\footnotetext{
${ }^{1}$ Besides the elimination of systemic risk, RTGS systems provide other benefits as well. For example, RTGS facilitates the development of payment versus payment (PVP) in foreign exchange trading and delivery versus payment (DVP) in securities markets (Bank for International Settlements 1992, 1996).

${ }^{2}$ In contrast, participants in net settlement systems typically grant each other credit implicitly during the period before final settlement. See Schoenmaker 1995 and Yamazaki 1996.
} 
different central banks, all of which are concerned with the cost of RTGS settlements, may arrive at different intraday credit policies. These policies can roughly be categorized into three groups: quantity limits, collateralized credit. and priced credit. although in practice, these policies are often used in combination.

The common example of a quantity limit policy is the Swiss Interbank Clearing (SIC) system. SIC imposes a zero limit on (e.g. does not offer) intraday credit, requiring participants to finance payments using only available balances. This has resulted in a very high turnover of reserves (about 60 times on an average day) and evidence of payment delays (Vital 1995). Japan's BOJ-NET is another example of a zero limit on intraday credit. This policy may have contributed to the designated-settlement-time (net) component of BOJ-NET predominating over the real-time (RTGS) component. ${ }^{4}$

Collateralized intraday credit appears to be the emerging dominant policy among EU and many other central banks implementing RTGS systems. All the European Union countries plan to provide some form of collateralized intraday credit for participants in their RTGS systems. The nature of these collateral arrangements typically involve either pledging collateral to the central bank or entering into an intraday repurchase agreement (repo) with the central bank.

In contrast, the Federal Reserve has not expressly chosen to adopt a policy of collateralizing all intraday credit. Instead, the Federal Reserve uses a combination of policies. In addition to using quantity limits and collateral, the Federal Reserve prices intraday credit at an administered rate of 15 basis points on an annual basis. ${ }^{5}$

These three different policy tools -- quantity limits, collateralized credit, or priced credit -- impose different implicit and explicit liquidity costs on RTGS participants. As will be developed below, these different policies also involve differences in who bears the credit risk

\footnotetext{
3 When a bank queues payments, then strictly speaking, the payments are not processed in "real-time". In general, therefore, a RTGS system that has queuing will not strictly be real-time.

${ }^{4}$ BOJ-NET consists of two settlement options - a designated net settlement option and a RTGS option. An overwhelming share of volume is processed using the designated net settlement option. (See Kamata 1990).

${ }^{5}$ This intraday price applies to the average intraday credit extended to a bank (less a deductible) without differentiation as to the payment transfer system (e.g., Fedwire, check, ACH) that generates the demand for intraday credit. A significant share of the credit, however, is due to the transfer of both funds and securities over
} 
of a possible intraday bank failure and the likelihood of payment system gridlock. It is possible that different central banks view payment related credit risk, systemic risk, and gridlock differently, and that these differences may have led to different intraday credit policies. By formalizing the interaction of bank payment activity, liquidity management, and the objectives of the central bank, it is the goal of this paper to explain why different central banks have chosen different policies when faced with a common objective of reducing the cost of using RTGS.

The paper is organized as follows. Section 2 develops a model of commercial bank liquidity management that takes central bank intraday credit policy as given. Assumptions regarding the nature of payments and the policy tools available to the central bank are outlined. Section 3 explains the relationship between central bank intraday credit policy and a commercial bank's optimal use of intraday credit. Section 4 formally specifies the objectives of a central bank with regard to intraday credit policy. Using these objectives, we describe sufficient conditions for the features of technology and the types of preferences that would rationalize, within the context of the model, various intraday credit policies.

\section{The Model Environment}

The intraday banking model that follows can be viewed as a model of a representative institution that participates actively in a country's RTGS system. For simplicity, we refer to this institution as a bank. We assume for simplicity that overnight balance sheet decisions are made independently from intraday liquidity management decisions. From the perspective of the bank's intraday liquidity manager, the asset and liability mix of the bank are exogenously given at the start of the business day and were optimally chosen, conditional on interest rates, reserve and capital requirements, and expected intraday liquidity needs. In general, the bank's overnight balance sheet will consist of a given mix of loans, securities, reserves, demand and time deposits, and various types of longer-term debt and equity. As a convenient baseline, we assume the bank's overnight balance sheet was chosen when unlimited. free intraday credit

the RTGS system, Fedwire. A description of the Federal Reserve's intraday credit policy can be found in Board 
was provided by the central bank. With this assumption, intraday balance sheet adjustments undertaken to manage payment flows in response to unexpected payment patterns or to intraday credit quantity limits, collateral requirements. or prices, can all be modeled as costs to the bank relative to this baseline.

Let $e$ denote the level of assets on the bank's overnight balance sheet that are eligible for use as collateral on the real-time gross settlement system. These eligible assets typically consist of short-term securities or other highly liquid assets. Let $r$ denote the bank's overnight reserves that it can use for settlement of its payments during the day. These reserves are assumed to pay interest at an overnight rate $i^{r}$, which is below that of the rate on the eligible assets, $i^{e}$. The model does not require that reserves pay any interest, or that there are any positive reserve requirements. Essentially, though, these assumptions place an upper bound on the cost of intraday credit. That is, the bank can always hold additional overnight reserves at an opportunity cost of $i^{e}-i^{r}$.

\subsection{Payments and Liquidity}

The representative bank is faced with an exogenous and uncertain amount of payment demand $\tilde{T} \cdot{ }^{6}$ The distribution of $\tilde{T}, f_{T}(\tilde{T})$, is known to the bank. ${ }^{7}$ Uncertainty arises because some payment flows are driven by the bank's customers and therefore cannot be perfectly predicted. We also assume that payment demand is inelastic with respect to the price that the bank may charge its customers for processing a payment. ${ }^{8}$ We further assume that the bank supplies payment services perfectly elastically so that realized payment demand determines the payments processed. To immediately process a payment on the Real-Time Gross Settlement (RTGS) system, the bank needs to either have sufficient balances in its

of Governors 1996.

${ }^{6}$ As an empirical matter, however, the elasticity of payment demand and supply with respect to intraday credit cost may be an important consideration determining the overall impact of credit policy on bank costs.

${ }^{7}$ The transaction demand may also include payments generated by the bank's own activity such as proprietary foreign exchange and securities trading and fed funds purchases. What is necessary for the model is that either (a) these payment flows are not a function of intraday credit policy or (b) these payment flows are being driven by business decisions that are treated separately from liquidity management issues. Although potentially suboptimal, this does seem a reasonable approximation to actual practice. 
reserve account or be granted intraday credit by the central bank to finance the payment. We assume that once the bank has the necessary funds and has paid any costs associated with acquiring liquidity, the marginal transaction cost of making payments is zero.

Define $Z$ to be the bank's desired use of intraday, central bank provided credit. ${ }^{9}$ As will be described formally in Section 3, the bank's desired use of intraday credit will depend on the cost of such credit, which in turn depends on a variety of factors including central bank intraday credit policy. Because of the assumption of no transaction costs, if unlimited intraday credit were provided free by the central bank, the commercial bank would simply process each and every payment as it arrived, borrowing intraday credit from the central bank whenever the payment amount exceeded its reserve account balance. Define $B(\tilde{T})$ to be the amount of credit that the commercial bank would be expected to use when intraday credit is both unlimited and free. That is, with free and unlimited intraday credit, the bank would expect to use intraday credit in an amount $Z$, equal to the baseline level, $B(T)$. We expect that intraday credit demand is positively related to payment flows, and therefore assume that $B(\tilde{T})$ is increasing in $\tilde{T}$. In the absence of any explicit quantity limits, collateral requirements, or prices, the bank can choose to use an amount of intraday credit $Z=B(\tilde{T})$ at no cost.

Note that when unlimited. intraday credit is provided at no cost, desired credit usage $Z$ is potentially limitless. With very high payment volume, desired intraday credit use in the baseline case would become indefinitely large. The bank can, however, process any given payment volume $\tilde{T}$ using less intraday credit than $B(\tilde{T}) .{ }^{10}$ We assume that liquidity management costs are incurred when the bank tries to reduce intraday credit usage below what would be incurred if intraday credit were free and unlimited, $B(\tilde{T})$. We specify a liquidity management cost function $L(B(\tilde{T})-Z)$, that is an increasing and convex function of its argument, intraday credit reduction, $B(\tilde{T})-Z$. Thus, $L$ is decreasing and convex in desired

\footnotetext{
${ }^{8}$ The price that the bank charges for its payment processing is not modeled in this research. This assumption does not affect the qualitative results that follow.

${ }^{9}$ The model does not distinguish between peak and average credit use as is done by the Federal Reserve.

${ }^{10}$ The bank will want to do this when faced with quantity limits, collateral requirements, or prices.
} 
intraday credit $Z$. That is, using more credit to process a given level of payments lowers the bank's liquidity management cost.

Liquidity management costs may arise from the bank trying to more actively manage its incoming and outgoing payment orders. For example, the bank can delay sending an outgoing payment that would exceed its reserve balance until more incoming payments have been received. This payment management technique, known as queuing, is likely to frustrate the bank's customers interested in the timely processing of their payments. If such delays occur near the end of the business day, there is a greater likelihood of the payment not being processed until the following day. These delays may be damaging to the bank's reputation as a payment processor and may even result in legal claims against the bank. Liquidity management costs of managing payments may be more tangible, too. For instance, the bank may need to purchase a computer system or hire additional, well-trained liquidity managers to achieve a reduced need for intraday credit.

Liquidity management costs are imposed on expected intraday credit demand, $Z$. Actual intraday credit use, which we denote $\tilde{Z}$, however, does not equal the bank's desired intraday credit use. Since incoming payments may arrive at unpredictable times and outgoing payments may be affected by operational difficulties, we express actual intraday credit usage $\tilde{Z}$ by the equation

$$
\tilde{Z}=Z+\varepsilon_{Z}
$$

We assume that $E\left(\varepsilon_{Z}\right)=0$ and that $\varepsilon_{Z}$ has a symmetric, single peaked, continuously differentiable probability density function $f_{Z}\left(\varepsilon_{Z}\right)$, which is known to the bank.

\subsection{Central Bank Intraday Credit Policy Tools}

The central bank in the model is assumed to have three tools at its disposal to affect the amount of intraday credit supplied to the commercial bank. First, it can charge a price $p$ on all intraday borrowings. Second, it can set a quantity limit of $\bar{Z}$. We assume that if the bank 
uses more intraday credit than $\bar{Z}$, it must pay a cost $q$, which without loss of generality, we assume to be fixed. ${ }^{11}$ We assume that the cost $q$ is sufficiently high that the bank does not choose an expected level of intraday credit $Z>\bar{Z}$. That is, the bank does not expect to violate its cap. Define the indicator function $I_{\bar{z}>\bar{Z}}$ to be equal to $l$ whenever actual intraday credit usage exceeds the bank's quantity limit $(\tilde{Z}>\bar{Z})$ and $O$ otherwise. We therefore can specify the costs of quantity limits as $q I_{\bar{z}>\bar{z}}$.

The third intraday credit policy at the disposal of the central bank is that it can require that a share $h, 0 \leq h \leq 1$, of the intraday credit be backed by collateral. We have assumed that the bank's overnight portfolio has assets in amount $e$ that are eligible for use as collateral. Without loss of generality, we assume that the cost of pledging these assets is proportional to the amount pledged. Specifically, the cost of pledging assets already on the overnight balance sheet in an amount $\left(Z+\varepsilon_{Z}\right) h$ is equal to $c\left(Z+\varepsilon_{Z}\right) h$. The marginal cost of pledging assets that are on the overnight balance sheet, $c$, represents the opportunity cost to the bank of no longer being able to use these assets in a repurchase agreement or to lend these assets in established markets. If collateral is needed in excess of $e$, the bank must acquire additional eligible assets. We assume that the cost of doing so can be expressed by the function $C_{1}\left(\left(Z+\varepsilon_{Z}\right) h-e\right)$ where the function $C_{1}(\cdot)$ is assumed to be increasing and convex. ${ }^{12}$ The cost function $C_{1}(\cdot)$ includes the opportunity costs associated with holding more securities or reserves than originally desired in the overnight portfolio and the costs of borrowing assets in overnight (or possibly intraday) markets. With these assumptions, the total cost of satisfying the collateral requirement, given by the function $C_{0}(\cdot)$, can be specified by

$$
C_{0}\left(\left(Z+\varepsilon_{Z}\right) h\right)=\left\{\begin{array}{cc}
c\left(Z+\varepsilon_{Z}\right) h & ,\left(Z+\varepsilon_{Z}\right) h \leq e \\
c\left(Z+\varepsilon_{Z}\right) h+C_{1}\left(\left(Z+\varepsilon_{Z}\right) h-e\right), & \left(Z+\varepsilon_{Z}\right) h>e
\end{array}\right.
$$

\footnotetext{
${ }^{11}$ A sufficiently high value of $q$ would be equivalent to the quantity limit being a binding constraint.

12 If the bank holds additional reserves as a substitute for its collateral requirement, then $C_{1}(\cdot)=\left(Z+\varepsilon_{Z}\right) h\left(i^{e}-i^{r}\right)$.
} 


\section{Analysis of Bank Behavior}

A commercial bank's use of intraday credit depends crucially on the central bank policy variables, $\bar{Z}, p, h$, and $q$. The purpose of this section is to analyze how these central bank policies affect a commercial bank's optimal use of intraday credit. To maintain generality, the model assumes that the central bank has chosen to use a combination of prices, collateral requirements, and quantity limits, although in practice, some of these policies may not be used. How a central bank might actually choose $\bar{Z}, p, h$, and $q$ optimally will depend, in part, on how commercial banks respond to the policy choice. Thus, the analysis of a commercial bank's response to intraday credit policies is a fundamental ingredient into the central bank's choice of intraday credit policy that will be discussed in Section 4 .

In the model, a representative bank must choose its target use of intraday credit, $Z$. knowing the central bank choices of $\bar{Z}, p, h$, and $q$, as well as the distributions of $\tilde{T}$ and $\varepsilon_{Z}$. Then, both $\tilde{T}$ and $\varepsilon_{z}$ are realized. Finally, the bank pledges any necessary collateral at the cost $C_{0}(\cdot)$. The model's timing assumptions are consistent with typical intraday bank knowledge. Were this a multi-period intraday model, the bank might be able to react to both $\tilde{T}$ and $\varepsilon_{Z}$ after they were realized, thereby "choosing" a different level of credit each day. The focus of this paper, however, is the choice of optimal intraday credit policy. Such policy decisions are likely made considering what the aggregate, or typical response of the banking industry may be. Therefore, we believe one should view the liquidity management costs in the model as longer term investment in the physical capital (e.g. computer systems) and the human expertise (e.g. employees) necessary to manage a bank's liquidity intraday. With this interpretation, the model's analysis applies to a bank's typical use of intraday credit and not to how day to day shocks may cause a bank's intraday credit demand to fluctuate.

The representative bank takes the central bank choices of $\bar{Z}, p, h$, and $q$ as given, and is assumed to minimize the expected cost of its payments operations. Costs consist of four elements. First, the bank may incur liquidity management costs $L$. Second, the bank is charged a price $p$ for its use of credit. Third, the bank may need to pledge collateral at a cost 
$C_{0}(\cdot)$. Finally, the bank faces the quantity limit costs in the amount $q I_{\bar{z}>\bar{z}}$. Formally, the bank's objective is to solve

$$
{ }_{Z}^{\operatorname{Min}} E\left[L(B(\tilde{T})-Z)+p\left(Z+\varepsilon_{Z}\right)+C_{0}\left(\left(Z+\varepsilon_{Z}\right) h\right)+q I_{\dot{Z}>Z}\right]
$$

The first order condition for this problem is

$$
E\left[L^{\prime}(B(\tilde{T})-Z)\right]=p+h E C_{0}^{\prime}\left(\left(Z+\varepsilon_{Z}\right) h\right)+q f_{Z}(\bar{Z}-Z) .
$$

The left-hand side of (4) is the expected marginal liquidity management cost savings obtained by using more intraday credit. As the bank desires to use more intraday credit $Z$, it can reduce its expected liquidity management costs by an amount given by $E\left[L^{\prime}(B(\tilde{T})-Z)\right]$. The first term on the right hand side of (4), $p$, represents the expected marginal policy related costs of prices. The marginal expected collateral cost is $h E C_{0}{ }^{\prime}\left(\left(Z+\varepsilon_{Z}\right) h\right)$ where

$$
C_{0}^{\prime}(\cdot)=\left\{\begin{array}{cl}
c & ,\left(Z+\varepsilon_{Z}\right) h \leq e \\
c+C_{1}^{\prime}\left(\left(Z+\varepsilon_{Z}\right) h\right) & ,\left(Z+\varepsilon_{Z}\right) h>e
\end{array} .\right.
$$

That is, there is a constant marginal cost for using assets that were already on the bank's overnight balance sheet. The marginal cost of collateral increases when the bank needs to acquire additional collateral. The expected marginal cost of quantity limits is the fixed cost of failing the limit, $q$, multiplied by the expected marginal probability of failing the quantity limit. The marginal probability of failing the quantity limit is simply the probability distribution of $\varepsilon_{Z}$ evaluated at the bank's expected distance from the quantity limit, $\bar{Z}-Z$.

The bank's choice of intraday credit is shown graphically in Figure 1. Without loss of generality, we draw Figure 1 assuming that eligible assets on the overnight balance sheet $e$ are 
all exhausted before a noticeable increase in the likelihood of violation of the quantity limit. In Figure 1, Region 1 corresponds to a level of intraday credit that is below the level of eligible assets $e$ on the bank's overnight balance sheet. Therefore, the policy related costs consist of the central bank imposed price $p$, and the opportunity cost of pledging assets that are on the overnight balance sheet, $h c$. In Region 2, the marginal cost of obtaining credit increases as banks must incur costs to obtain additional collateral. That is, Region 2 incorporates where $C_{0}^{\prime}(\cdot)>c$. Region 3 includes the expected marginal cost of failing the central bank intraday credit quantity limit. Again, the ordering described here is dependent upon the relative magnitudes of the marginal costs of collateral and quantity limits, but the qualitative results presented below would still follow.

Figure 1: The Determination of Intraday Credit Use

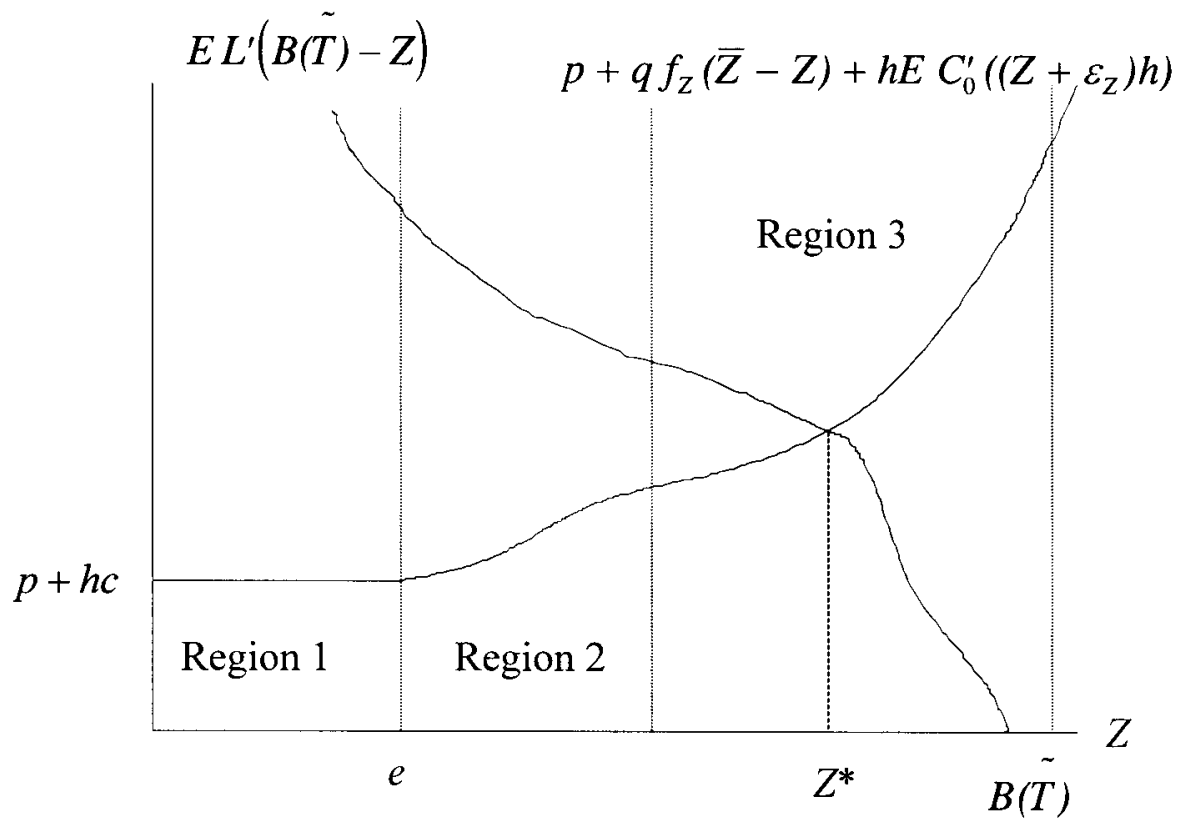

\section{Analysis of Central Bank Behavior}

The previous section described the optimal behavior of a representative commercial bank, taking central bank policy decisions as exogenously given. The commercial bank's 
choice of intraday credit use was selected by balancing the private costs and benefits of intraday credit use, i.e. the costs and benefits that enter into the commercial bank's objective function such as the costs of managing liquidity and pledging collateral. However, the policy decisions of a central bank also consider payment system externalities. Therefore, a central bank's objective function will include the social costs and benefits of extending intraday credit. Because some social costs are viewed as externalities by the private sector, they do not play a role in a bank's decision as to how much intraday credit to use, given the central bank's ultimate choice of its policy.

In many respects, central bank objectives are dictated by statute. For example, in some countries, the central bank may be prohibited from extending credit of any kind that is not backed by certain types of collateral. In other cases, central banks may have more flexibility in the choice of intraday credit policies as part of the design of a RTGS payment system, or as part of payment system policy more generally. For simplicity, we assume that the objectives that determine the central bank's optimal choice of intraday credit policy are independent from all other objectives of the central bank and therefore, can be considered in isolation. ${ }^{13}$

\subsection{Central Bank Objectives:}

Central banks presumably are interested in the efficient provision of payment services by the commercial banking sector, i.e. in private costs and benefits. However, central banks may have differing views as to whether or not the cost savings or other economic gains to the commercial banking sector arising from central bank provided intraday credit are social cost savings or simply the provision of a subsidy. To allow for both possibilities, we include the minimized value of bank costs in the central bank objective function, denoted by the function $P^{*}(\bar{Z}, p, h, q)$. That is, the function $P^{*}$ represents the commercial bank's costs at its optimal

\footnotetext{
${ }^{13}$ In particular, we do not consider how the central bank's intraday credit policy may affect its ability to conduct monetary policy operations. As twenty-four hour intraday money markets do not yet exist, and because central banks typically charge a substantial penalty for converting intraday credit into overnight credit, we assume that there can be a complete separation between central bank objectives during the day and central bank objectives relating to monetary policy operations. One possible effect of intraday credit policy would be to encourage the development of an intraday money market. This would have consequences for monetary policy that likely enter the central bank utility function. The policies analyzed here, however, are assumed to supply intraday credit at an effective price below what would warrant the development of such an intraday market.
} 
choice of $Z$, given the central bank's choice of $\bar{Z}, p, h$, and $q$. When a central bank views commercial bank cost savings arising from intraday credit use as a social gain, the central bank's social costs will be increasing in $P^{*}$. When a central bank views commercial bank cost savings arising from intraday credit use as a subsidy, the central bank's social costs will be decreasing in $P^{*}$.

The central bank, acting in the public interest, also considers other social costs when determining its intraday credit policy -- payment system gridlock, systemic risk, direct credit risk to the central bank, and the costs associated with implementing a credit policy. These concerns are part of the central bank objective function, yet were not considered by the commercial bank when it chose its optimal intraday credit use. The first social cost of intraday credit policy that the model considers is payment system gridlock. Consider a bank that faces policy related costs in obtaining intraday credit. The bank may desire to delay its outgoing payments and wait until incoming payments have been received to conserve on its intraday credit use. The cost of managing payments in this way is what gave rise to the $L(B(\tilde{T})-Z)$ function discussed before. However, such behavior can lead to gridlock in the payments system. That is, if every commercial bank were to wait for incoming payments, literally no payments would be made. This is an externality from the perspective of the individual bank. This is because when a bank delays sending an outgoing payment, it does not consider the impact of this decision on the receiving bank's reserves and thus on its ability to send its outgoing payments. ${ }^{14}$

Acting in the public interest, the central bank may wish to discourage payment delays through its credit policy. Thus, from the central bank's point of view, there is a function $S_{G}\left(Z^{*}(\bar{Z}, p, h, q)\right)$. which describes the social cost of potential gridlock. Note the function $S_{G}$ is a function of the representative commercial bank's optimal choice of intraday credit $Z^{*}$, which in turn, is a function both of the technology of liquidity management, $L(B(\tilde{T})-Z)$, and of the central bank's intraday credit policy choices. We assume that $S_{G}$ is both decreasing and

\footnotetext{
${ }^{14}$ In a multi-bank model, with interaction among participants, the likelihood of gridlock may be related to the number of participants in a payment system as well as the size and distribution of the payments.
} 
convex in $Z^{*}$ to account for the fact that the potential social cost of gridlock approaches zero for a sufficiently high level of intraday credit provision. That is, the central bank incurs lower social costs of gridlock when it chooses its policy variables $\bar{Z}, p, h$, and $q$ at levels that encourage intraday credit use.

The model also considers the impact of its intraday credit policy on systemic risk. A central bank providing collateralized intraday credit may increase the uncollateralized credit exposures between banks that, all else equal, may increase systemic risk. When intraday credit is collateralized, intraday credit exposure is reduced for the central bank and potentially shifted to the pledging bank's other creditors, which could be other banks. This strengthens the link between the inability of one bank to repay its intraday credit and the health of other bank creditors, likely increasing systemic risk. For this reason, we assume that the central bank objective function includes a social cost that is a function of the level of collateralized intraday credit. This social cost of collateralized intraday credit is given by $S_{C}\left(h Z^{*}(\bar{Z}, p, h, q)\right)$ that we assume to be both increasing and convex. ${ }^{15}$

Another concern of a central bank may be its own intraday credit exposure. That is, the central bank is presumably averse to bearing direct credit risk, which, in the event of an intraday bank failure, would likely be born by taxpayers in general. That is, the central bank would suffer a loss that results in reduced central bank earnings returned to the government. The central bank objective function accounts for a disutility of bearing this direct credit risk. The increasing and convex cost function $S_{U}\left((1-h) Z^{*}(\bar{Z}, p, h, q)\right)$ represents the social costs of extending intraday credit that is not backed by collateral. ${ }^{16}$

One might suspect that the social costs of extending credit, whether collateralized or not, should be internalized by the commercial bank. Our model assumes that individual banks do not consider the systemic risk or central bank credit exposure implications of central bank credit policy. That is, these risks are implicitly not being priced by commercial bank creditors. We make this assumption because of the nature of intraday payments activity. Commercial banks typically do not disclose information regarding their daily intraday credit

\footnotetext{
${ }^{15}$ If there is a production cost of supplying collateralized intraday credit, this cost would be part of $S_{C}$.
} 
demands. Further, intraday borrowing, and the resulting collateralization and central bank credit exposure, can change significantly and unpredictably during the course of a single day. Our assumption, therefore, rests on our belief that creditors are unable to react to intraday changes in collateralized and uncollateralized intraday credit exposures.

Finally, we assume that the central bank is concerned with the cost of implementing its intraday credit policy. Although formal modeling of implementation costs is beyond the scope of this paper, such costs likely depend on the policy chosen, the RTGS system involved, and also on the central bank. For instance, a policy of setting a uniform price for intraday credit may have lower implementation costs than a quantity limit policy that requires the choice of both the level of the limit and the penalty for exceeding the limit. Such implementation costs may also depend on the technical capabilities of a country's RTGS system and on the number of active participants in the system. Implementation costs may also vary because central banks may require different costs to calculate reasonable estimates of the unobservable social costs of intraday credit. ${ }^{17}$ For the purpose of this paper, however, we simply define $\operatorname{IC}(\bar{Z}, p, h, q)$ to be the implementation cost of the credit policy consisting of $\bar{Z}, p, h$ and $q$, and assume that all else equal, the central bank prefers a policy that is less costly to implement.

\subsection{The Central Bank Objective Function}

Combining the elements discussed in Section 4.1, the central bank is assumed to choose its intraday credit provision policy to minimize the expected value of both the private (e.g. commercial bank) costs and the social costs of gridlock, collateralized credit extension, uncollateralized credit extension, and policy implementation. That is, the central bank solves:

$$
\underset{\bar{Z}, p, h, q}{\operatorname{Min}} E\left(\begin{array}{r}
P^{*}(\bar{Z}, p, h, q)+S_{G}\left(Z^{*}(\bar{Z}, p, h, q)\right)+S_{C}\left(h Z^{*}(\bar{Z}, p, h, q)\right) \\
+S_{U}\left((1-h) Z^{*}(\bar{Z}, p, h, q)\right)+I C(\bar{Z}, p, h, q)
\end{array}\right)
$$

\footnotetext{
${ }^{16}$ If there is a production cost of supplying uncollateralized intraday credit, this cost would be part of $S_{U}$.
} 
where $P^{*}$ represents minimized private (commercial bank) costs and $S_{G}, S_{C}$, and $S_{U}$ are the social costs of gridlock, collateralized credit extensions, and uncollateralized extensions, respectively, and $I C$ represents implementation costs. ${ }^{18}$

\subsection{The Central Bank Choice of Prices, Quantity Limits, or Collateral}

For a given set of parameter values, numerous functional form assumptions, and beliefs regarding implementation costs, one could determine the optimal central bank choice of $\bar{Z}, p, h$, and $q$. That is, the continuity assumed in this problem suggests that the optimal choice of intraday credit policy would consist of a strategy of taking collateral, pricing, and using quantity limits. Rather than solving for a general, social welfare maximizing intraday credit policy, our approach is to explain, within the context of the model, the various intraday credit policies that one observes in the G-10 countries. To this end, this section gives sufficient conditions in the model under which various choices of intraday credit policy would be made. As a comparative benchmark, we also consider the choice of unlimited, free intraday credit. For each of the six following policies, we use the notation $I C_{i}, i=1, \ldots, 6$ to represent the implementation costs associated with policy $i$.

Credit Policy 1: Unlimited, free, uncollateralized intraday credit.

Sufficient conditions for the central bank to choose unlimited intraday credit provision, without any prices, quantity limits, or collateral requirements are

\footnotetext{
${ }^{17}$ Implementation of the optimal credit policy may be further complicated if the costs of implementing various credit policies vary across days, or even intraday.

18 The assumption that the central bank minimizes expected costs is without loss of generality. The qualitative results still follow if the central bank's objective was to minimize any convex function of total private and social costs of intraday credit.
} 


$$
\begin{gathered}
\text { (a) }\left(P^{*}\right)^{\prime}>0 \\
\text { (b) } S_{\mathrm{C}}(\cdot) \rightarrow 0 \\
\text { (c) } S_{\mathrm{U}}(\cdot) \rightarrow 0 \\
\text { (d) } I C_{1}-\operatorname{Min}_{i \neq 1}\left\{I C_{i}\right\} \leq 0
\end{gathered}
$$

That is, a central bank would choose $\bar{Z}=\infty, p=0, h=0$, and $q=0$ if it viewed intraday credit related cost savings as social savings, there were no social costs of extending collateralized or uncollateralized intraday credit, and if the cost of implementing this policy was no greater than implementing any alternative policy. These conditions guarantee that a central bank would wish to minimize gridlock and commercial bank costs. This is achieved by simply providing unlimited credit at no cost. Currently, no G-10 central bank provides unlimited, uncollateralized, free intraday credit.

Credit Policy 2: Unlimited, priced, uncollateralized intraday credit.

Sufficient conditions for the central bank to choose unlimited, priced, intraday credit provision, without quantity limits or collateral requirements are

$$
\begin{gathered}
\text { (a) }(P *)^{\prime}=0 \\
\text { (b) } I C_{2}-\operatorname{Min}_{\substack{i \neq 2 \\
\text { (c) } S_{C}(.) \rightarrow \infty .}}\left\{I C_{i}\right\}<0
\end{gathered}
$$

That is, a central bank will choose $\bar{Z}=\infty, p>0, h=0$, and $q=0$ whenever it places a zero weight on credit related costs, when a pricing policy is the least costly policy to implement, and when the social cost of collateralized credit is high. ${ }^{19}$

19 If the central bank viewed the credit related cost savings as a subsidy, $P^{\prime}<0$, pricing would be preferred to both quantity limits and collateral. However, if the model permitted a central bank to charge different prices for different levels of intraday credit, then charging a single price would be dominated by a price discriminating policy that further reduced the presumed subsidy. Nevertheless, a single price policy may remain the optimal 
The first condition makes the central bank indifferent (excluding implementation costs) among policies that generate the same credit demand. The second condition makes the pricing policy the most cost effective policy choice. The final condition regarding the social costs of collateralized credit is sufficient for a central bank to provide credit uncollateralized. No G-10 central bank currently provides unlimited, uncollateralized, intraday credit for a price.

Credit Policy 3: Limited, free, uncollateralized intraday credit.

If we define $Z^{*}(\bar{Z}, q)$ to be the bank's optimal choice of intraday credit given the central bank's use of a quantity limit policy specified by the policy pair $(\bar{Z}, q)$, then sufficient conditions for the use of a quantity limit $\bar{Z}$ are

$$
\begin{gathered}
\left(\text { a) }\left(P^{*}\right)^{\prime}>0\right. \\
\text { (b) } S_{\mathrm{C}}(\cdot) \rightarrow \infty \\
\text { (c) } S_{\mathrm{U}}(B(\widetilde{T}))-S_{U}\left(Z^{*}(\bar{Z}, q)\right)>\left(S_{G}\left(Z^{*}(\bar{Z}, q)\right)-S_{G}(B(\widetilde{T}))+E \int_{Z^{*}(\bar{Z}, q)}^{B(\tilde{T})} L^{\prime}(B(\widetilde{T})-Z) d Z\right. \\
\text { (d) } I C_{3}-\operatorname{Min}_{i \neq 3}\left\{I C_{i}\right\} \leq 0
\end{gathered}
$$

The first condition, repeated from (7a), states that the central bank prefers policies that impose fewer intraday credit related costs on commercial banks. The second condition states that extending collateralized credit is socially very costly. This guarantees the choice of $h=0$. The third condition guarantees that employing quantity limits is preferred to unlimited, free, uncollateralized credit. That is, it guarantees that $\bar{Z}<\infty$. Specifically, (9b) states that the social cost savings achieved by the quantity limit exceeds the expected additional social cost of gridlock and the expected additional liquidity management cost imposed on the representative commercial bank that occurs as a result of the quantity limit. The last condition, repeated from ( $7 \mathrm{~d})$, states that the quantity limit policy is no more costly than any 
other policy. Quantity limit policies exist in Switzerland and Japan, where intraday credit is not provided by the central bank. Sufficient conditions for this choice are given in (9) with $\bar{Z}=0$.

Credit Policy 4: Unlimited, free, collateralized intraday credit.

Sufficient conditions for a central bank to choose a collateralization policy, that is, $\bar{Z}=\infty, p=0, h=1$, and $q=0$ are

$$
\begin{gathered}
(a)\left(P^{*}\right)^{\prime}>0 \\
(b) C_{0}(\cdot) \rightarrow 0 \\
(c) S_{\mathrm{I}}(\cdot) \rightarrow \infty \\
\text { (d) } S_{\mathrm{C}}(B(\widetilde{T}))-S_{C}\left(Z^{*}(\bar{Z}, q)\right)<\left(S_{G}\left(Z^{*}(\bar{Z}, q)\right)-S_{G}(B(\widetilde{T}))\right)+E \int_{Z^{*}(\bar{Z}, q)}^{B(\widetilde{T})} L^{\prime}(B(\widetilde{T})-Z) d Z \\
\text { (e) } I C_{4}-\prod_{i \neq 4}^{\operatorname{Min}}\left\{I C_{i}\right\} \leq 0
\end{gathered}
$$

Condition (10a) determines the central bank's views on intraday credit related costs. Condition (10b) says that satisfying collateral requirements are costless from the perspective of the commercial bank. This condition also minimizes the social cost of gridlock. The condition (10c) says that the social costs of uncollateralized credit are very high. This second condition is sufficient to require collateral for all intraday credit. The condition (10d) guarantees that an unlimited collateralization policy is preferable to a collateral policy with quantity limits, and depends on both central bank preferences and the technological costs of liquidity management. It states that the increased gridlock and liquidity management costs of limiting collateralized credit outweigh the social cost gains of doing so. The standard condition regarding implementation costs is given in (10e). Some countries, e.g. Germany, the Netherlands, Sweden, France, and the United Kingdom, have chosen this policy of extending intraday credit, fully collateralized, with neither a price nor quantity limit. 
Credit Policy 5: Limited, free, collateralized intraday credit.

Sufficient conditions for the combination of full collateralization and quantity limits are

$$
\begin{gathered}
(a)\left(P^{*}\right)^{\prime}>0 \\
(b) C_{0}(\cdot) \rightarrow 0 \\
\left(\text { c) } S_{\mathrm{U}}(\cdot) \rightarrow \infty\right. \\
(\text { d }) S_{\mathrm{C}}(B(\widetilde{T}))-S_{C}\left(Z^{*}(\bar{Z}, q)\right)>\left(S_{G}\left(Z^{*}(\bar{Z}, q)\right)-S_{G}(B(\widetilde{T}))\right)+E \int_{Z^{*}(\bar{Z}, q)}^{B(\tilde{T})} L^{\prime}(B(\widetilde{T})-Z) d Z \\
\text { (e) } I C_{5}-\operatorname{Min}_{\substack{i \neq 5 \\
\text { Min }}}\left\{I C_{i}\right\} \leq 0
\end{gathered}
$$

Conditions (11a), (11b), (11c), and (11e) are repeated from (10). The condition (11d) is the reverse of condition (10d) and states that the social cost gains of limiting collateralized credit exceed the increased gridlock and liquidity management costs of doing so. This policy choice has been made by the central banks in Belgium and Italy.

Credit Policy 6: Limited, priced, partially collateralized intraday credit.

$$
\begin{gathered}
\text { (a) }(P *)^{\prime}=0 \\
\text { (b) } I C_{6}-\operatorname{Min}_{i \neq 6}\left\{I C_{i}\right\}<0
\end{gathered}
$$

Conditions (12a) and (12b) are repeated from the unlimited, uncollateralized, priced intraday credit policy (Credit Policy 2). Eliminating the condition (8c) on the social cost of collateralized credit will generate a policy with limited use of collateral. A central bank would optimally choose the level of collateralization to equate the marginal social cost of uncollateralized credit with the marginal social cost of collateralized credit. That is, after setting prices and quantity limits to determine the quantity of intraday credit extended, the central bank will choose $h$ to satisfy $S_{C}^{\prime}(\cdot)=S_{U}^{\prime}(\cdot)$. Condition (12b) guarantees that Credit 
Policy 6 is preferred to all other policies. ${ }^{20}$ Prices, quantity limits, and partial collateralization are employed by the Federal Reserve. A complete description of the Federal Reserve's current policy can be found in Board of Governors 1996.

\section{Conclusion}

This paper modeled the different factors that go into the intraday credit policy decision of a central bank and rationalized, within the context of the model, various choices of intraday credit policy. Of particular importance to a central bank developing its intraday credit policy, the cost to a commercial bank for intraday credit was shown to not only depend on the explicit costs of prices and liquidity management, but also on the costs of collateral and expected costs of breaching quantity limits. The model demonstrated, too, that although each policy tool could achieve intraday credit reduction, each tool has different implications for systemic risk, the direct credit risk faced by the central bank, and potential payment system gridlock. As an empirical matter, the elasticity of payment supply and demand to the cost of payments processing, the marginal cost of raising collateral, and the marginal liquidity management cost of reducing intraday credit demand would be essential for determining both the bank's optimal use of intraday credit and the policy related costs incurred by the bank resulting from central bank intraday credit policy. In addition, the difficult task of further understanding central bank views on intraday credit related costs, the social cost of gridlock, the social costs of both collateralized and uncollateralized central bank credit, and the costs of implementing various policies would be necessary to determine the optimal intraday credit policy for a central bank.

20 Within the context of the model, a pricing policy (with or without collateral) would appear to dominate a pricing and quantity limit policy (with or without collateral). Comparing the conditions in (7) with those in (12), it seems reasonable that a policy of pricing alone would be less costly to implement than a policy of prices and limits. Quantity limits, however, serve purposes beyond those described in the model such as protecting the central bank against troubled institutions intentionally borrowing large quantities of intraday credit before failing. These added benefits may outweigh the additional implementation costs. 


\section{References}

Angelini, Paolo and Curzio Giannini, "On the Economics of Interbank Payment Systems," Temi di Discussione \#193, Banca d'Italia 1993.

Banca d'Italia, Interbank Payments in Italy: Lines of Reform 1995.

Bank for International Settlements, "Real-Time Gross Settlement Systems," 1997. , "Settlement Risk in Foreign Exchange Transactions," 1996. , "Statistics on Payment Systems in the Group of Ten Countries," 1995. , "Delivery Versus Payment in Securities Settlement Systems," 1992.

Berger, Allen N., Diana Hancock, and Jeffrey C. Marquardt, "A Framework for Analyzing Efficiency, Risks, Costs, and Innovations in the Payment System," Journal of Money Credit and Banking, 28, 1996, 696-732.

Board of Governors of the Federal Reserve System, "Overview of the Federal Reserve's Payments System Risk Policy,” 1996.

Borio, C.E.V. and Paul Van den Bergh, "The Nature and Management of Payment System Risks: An International Perspective," BIS Economic Papers \#36, 1993.

European Union, Report to the Committee of Governors of the Central Banks of the Member States of the European Economic Community on Minimum Common Features for Domestic Payment Systems, Working Group on EC Payment Systems, 1993. , Report to the Committee of Governors of the Central Banks of the Member States of the European Economic Community on Issues of Common Concern to EC Central Banks in the Field of Payment Systems, Ad Hoc Working Group on EC Payment Systems, 1992.

Faulhaber, Gerald R., Almarin Phillips, and Anthony M. Santomero, "Payment Risk,

Network Risk, and the Role of the Fed," in Humphrey ed. The US Payment System: Efficiency, Risk, and the Role of the Federal Reserve, 1989.

Gianninni, Curzio and Carlo Monticelli, "Which TARGET for Monetary Policy in Stage Three? Issues in the Shaping of the European Payment System," Banca d'Italia, Temi di Discussione del Servizio Studi, Number 257, 1995. 
Hancock, Diana and James A. Wilcox, "Intraday Management of Bank Reserves: The Effects of Caps and Fees on Daylight Overdrafts," Journal of Money, Credit, and Banking, 28, 1996, 870-908.

Horii, Akinari and Bruce J. Summers, "Large-Value Transfer Systems," in Bruce J. Summers ed. The Payment System: Design, Management, and Supervision, 1994, 73-88.

Humphrey, David B., "Payment Systems: Principles, Practice, and Improvements," World Bank Technical Paper 260, 1995.

"Market Responses to Pricing Fedwire Daylight Overdrafts," Federal Reserve Bank of Richmond Economic Review, 1989, 23-34.

Juncker, George R., Bruce J. Summers, and Florence M. Young, “A Primer on the Settlement of Payments in the United States," Federal Reserve Bulletin, 1991, 847-858.

Kamata, Sawaichiro, "Managing Risk in Japanese Interbank Payments Systems," Federal Reserve Bank of San Francisco Economic Review, 1990, 18-32.

Marquardt, Jeffrey C., "Payment System Policy Issues and Analysis," in Bruce J. Summers ed. The Payment System: Design, Management, and Supervision, 1994, 116-144.

Mengle, David L., David B. Humphrey, and Bruce J. Summers, "Intraday Credit: Risk, Value, and Pricing," Federal Reserve Bank of Richmond Economic Review, 1987, 3-14.

Padoa-Schioppa, Tommaso, "Update on Risks in Large-Value Payment Systems," Payment Systems Worldwide, 1992, 27-32.

Richards, Heidi W., "Daylight Overdraft Fees and the Federal Reserve's Payment System Risk Policy," Federal Reserve Bulletin, 1995, 1065-1077.

Rochet, Jean-Charles and Jean Tirole, "Controlling Risk in Payment Systems," Journal of Money, Credit, and Banking, 28, 1996, 832-861.

Schoenmaker, Dirk, "A Comparison of Alternative Interbank Settlement Systems," LSE Financial Markets Group Discussion Paper Series \#204, 1995.

Summers, Bruce J., "The Payment System in a Market Economy," in Bruce J. Summers ed. The Payment System: Design, Management, and Supervision. International Monetary Fund, 1994. 
, "Clearing and Payment Systems: The Role of the Central Bank," Federal Reserve Bulletin, 1991, 81-91.

Van den Bergh, Paul, "Operational and Financial Structure of the Payment System," in Bruce J. Summers ed. The Payment System: Design, Management, and Supervision. International Monetary Fund, 1994.

Van Hoose, David D., "Bank Behavior, Interest Rate Determination, and Monetary Policy in a Financial System with an Intraday Federal Funds Market," Journal of Banking and Finance, 343-365, 1991.

Vital, Christian, "The Architecture of Real-Time Gross Settlement Systems," Presentation at the Hong Kong Monetary Authority Seminar on Global Payment Systems, 1995.

Yamazaki, Akira, "Foreign Exchange Netting and Systemic Risk," Institute for Monetary and Economic Studies Discussion Paper 96-E-23, Bank of Japan, 1996. 